City University of New York (CUNY)

CUNY Academic Works

1986

\title{
Ten-year consistency in neurological test performance of children without focal neurological deficit
}

Stephen Q. Shafer

Columbia University

Cornelius Stokman

Columbia University

David Shaffer

Columbia University

Stephen K-C Ng

Columbia University

Patricia A. O'Connor

Russell S

See next page for additional authors

\section{How does access to this work benefit you? Let us know!}

More information about this work at: https://academicworks.cuny.edu/cc_pubs/285

Discover additional works at: https://academicworks.cuny.edu

This work is made publicly available by the City University of New York (CUNY).

Contact: AcademicWorks@cuny.edu 
Authors

Stephen Q. Shafer, Cornelius Stokman, David Shaffer, Stephen K-C Ng, Patricia A. O'Connor, and Irvin Sam Schonfeld 


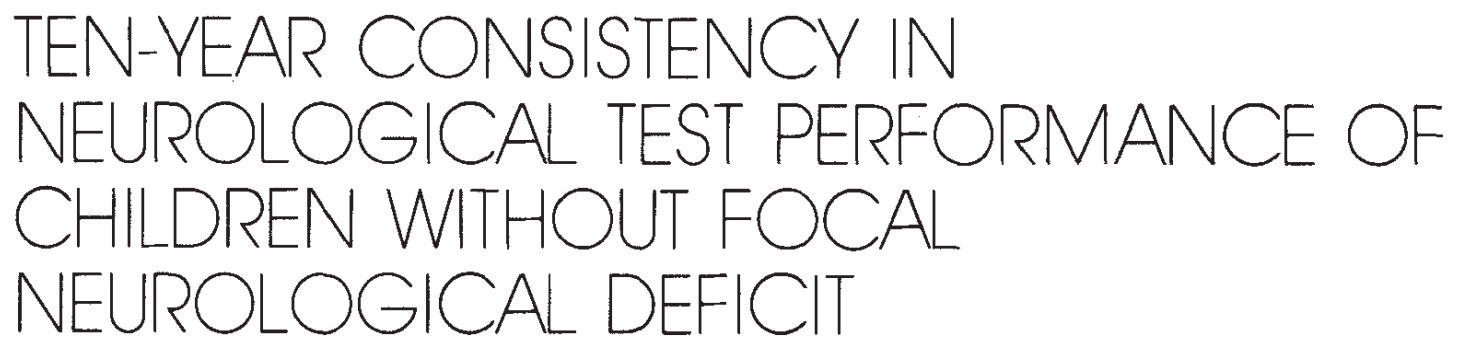

Stephen $Q$. Shafer

Cornelis J. Stokman

David Shaffer

Stephen $\mathrm{K}$-C. $\mathrm{Ng}$

Patricia A. O'Connor

Irvin S. Schonfeld

Neurological findings such as dysdiadochokinesis or dysgraphesthesia in persons of norma 1 IQ who have no localized abnormalities have been associated repeatedly with cognitive, behavioral or emotional deviancy (Adams et al. 1974, Quitkin et al. 1976, Shaffer et al. 1984). Although in our reviews of the 'soft signs' arena (Shaffer 1978, Shafer et al. 1984) we have noted many methodological variations in sample selection, measurement and analysis which compromise the validity of individual studies, the consistency of the relationship across many studies speaks strongly for an association. We explored this association by a follow-up study to see how well minor neurological dysfunction in middle childhood predicts later emotional and neurological status. The longitudinal design also gives a perspective on the natural history of socalled 'soft signs' through adolescence by means of three questions of developmental interest: (1) in what proportion of individuals do soft signs disappear between the ages of seven and 17 ?; (2) how do persons who become signfree in that interval differ from those whose suboptimal performance persists?; and (3) what is the meaning of de novo appearance of suboptimal neurological test performance after age seven?
The correlates and antecedents of soft signs are obscure. To some extent they are familial: there is no evidence that they are related to perinatal morbidity (Nichols and Chen 1981, Chapter 13). The natural history of these findings is almost unknown. Some researchers assert that soft signs in seven-year-olds are simply maturational lags which will disappear. Consonant with this is the observation in cross-sectional studies that older children have fewer soft signs than younger ones (Shapiro et al. 1978). Decreases in the proportion of tasks poorly performed as the child matures have also been documented in the largest longitudinal study (Hertzig 1982). A corollary to the maturational lag hypothesis, however, is that soft signs would not be acquired after (say) age seven: their appearance de novo would have to be interpreted as being due to either measurement error or experiential factors like recent drug usage or head trauma.

Re-examination of a sample of children from the National Collaborative Perinatal Project (NCPP) offered an opportunity to study the persistence or appearance in adolescence of non-normative performances on neurological examination. The children followed were from a larger sample generated before birth and thus not initially selected because of 
neurological abnormalities. The six null hypotheses to be tested were that, at age 17, children who had had soft signs at age seven would be neurologically indistinguishable from or superior in performance to peers who had been signfree at age seven on each of six separate measurements-astereognosis, dysgraphesthesia, dysdiadochokinesis, mirror movements, motor slowness and involuntary movements. The alternative hypothesis was that children who had had signs at age seven would score worse than controls at 17 . We also examined correlates of the appearance of soft signs after age seven in children sign-free at seven, and the converse-correlates of the disappearance of these findings.

\section{Methods}

Subjects

The starting point of the current study was the neurological examination done at Columbia-Presbyterian Hospital in 1969 and 1970 on the seven-year-olds in the Columbia cohort of the NCPP.

The NCPP originally enrolled some 54,000 women registering for prenatal care at 15 university hospitals around the country between 1958 and 1963 . Women were usually sampled on an every $\mathrm{n}^{\text {th }}$ registrant basis. At each center the infants were followed for seven years, with special attention given to developmental and neurological milestones. The Columbia cohort, numbering over 2000 mothers, is described in detail elsewhere (O'Connor et al. 1986). The group examined at age seven included 88 per cent of the black children born in 1962 and 1963 and known to have survived to 1970.

The seven-year neurological examination followed the NCPP protocol (PED-76), and was performed by a boardcertified pediatrician who was unaware of the child's records. We sought to reexamine in their eighteenth year all individuals from the Columbia cohort of the NCPP with these characteristics: (a) born in 1962 or 1963; (b) black and English-speaking; (c) noted at age seven to have one or more of eight selected neurological findings (see Table I); and (d) having no clear-cut history of a neurological disorder apt to interfere with
Sixty boys and 26 girls comprised the index group. For each, the sex-matched black born next into the cohort who had been free of any index neurological and focal findings at age seven was entered into the 17-year-old group of comparison adolescents. No substitute was allowed if that individual could not be re-examined.

The proportion of children at Columbia judged abnormal at age seven on one or more neurological soft signs was relatively high compared to that at other centers, seemingly because there was a lower threshold to certain items at Columbia (Nichols and Chen 1981, p. 46). This threshold, as Table II shows, is not associated with race. Black males were most often sign-positive, black females least often. The low threshold means that not all the index children were 'clumsy', but all were less adept than most of their peers.

The criterion items from the seven-year examination and the number of boys and girls with each are shown in Table I. 'Awkwardness' and dysdiadochokinesis, singly or together, accounted for the majority of the children of both sexes who were 'positive' at age seven. These two features were modestly related to each other in boys; other inter-relationships were negligible.

Can a suspicious history, regardless of findings, make someone ineligible for soft signs? Uncertain who might be excluded on such grounds, we identified 10 children, all boys and all sign-positive at age seven, who were either of borderline IQ at that age or who had histories of neurological illness before age seven that might influence both neurological performance at age seven and later outcome measures. These marginal cases were found from the interdisciplinary code' of the NCPP and confirmed by review of the original records.

Four of these marginal children at age seven had had both verbal and performance IQ slightly below 70. Two others had had head circumferences more than 2.5 SD below the age mean. One of these had dull-normal intelligence, the other a full-scale IQ of 62 . Another child at seven had had a very large head, rickets and weakness (left more than right) of both legs. As an adolescent he had a slight 
TABLE I

Neurological signs among 60 boys and 26 girls subjects at age seven

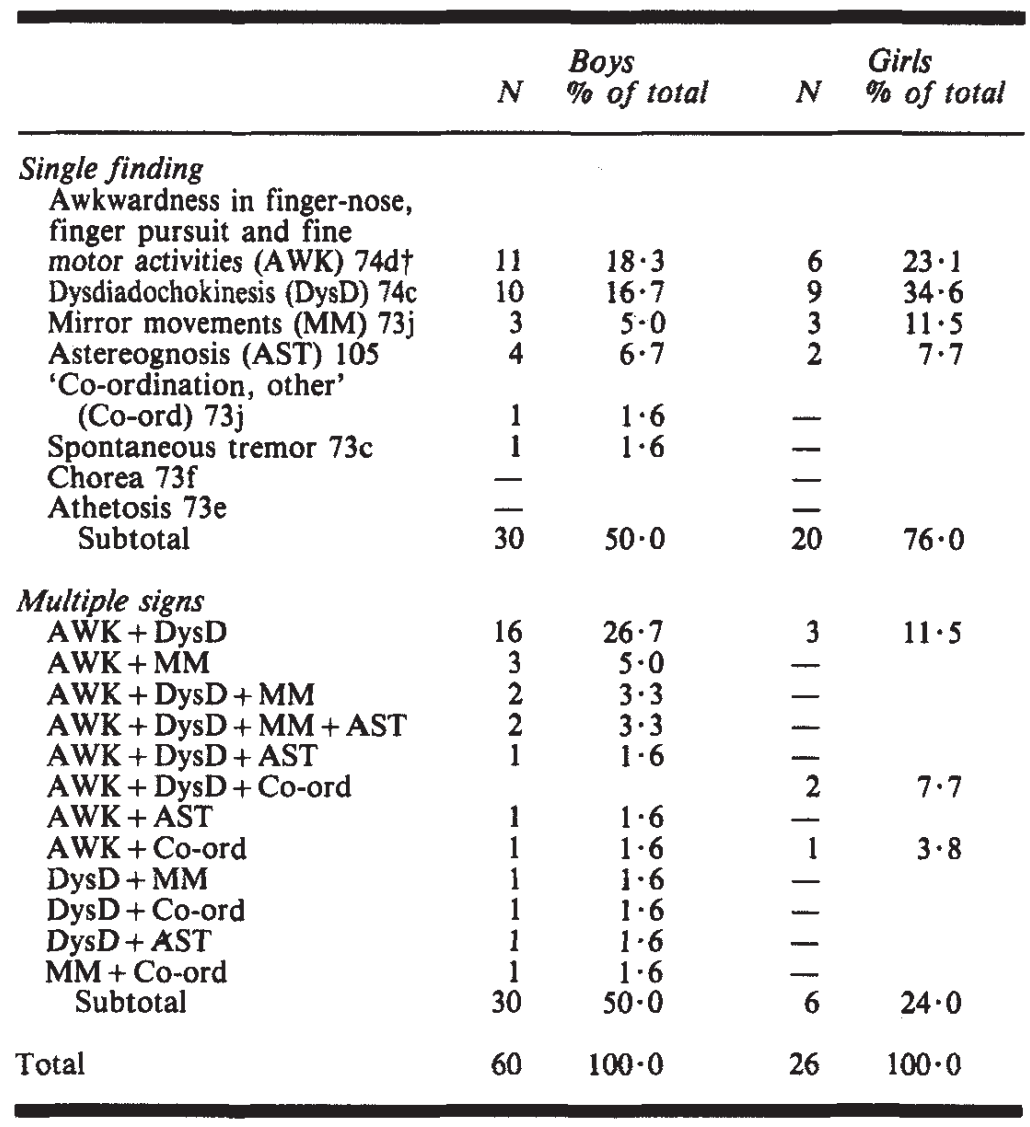

†The two-digit, one-letter code identifies the item in the NCPP PED-76 protocol on which our criterion was based.

left hemiparesis. The eighth, jaundiced at birth, had had herpes meningoencephalitis with a seizure at age one, followed by a seizure at age two. Two others had had partial elementary motor seizures, one with fever and one without. Children with only simple febrile convulsions were kept in the analysis throughout.

\section{Follow-up}

Fifty-seven of the 60 index males sought at age 18 consented to re-examination, as did 55 comparison males. Among the females the corresponding figures were 25 of 26 in the index group and 22 comparison females. Most participants were brought to the testing suite at the project's expense, though some were visited elsewhere by the project staff. We obtained informed consent from all participating teenagers and their parents, all of whom received $\$ 10$ compensation. All forms were approved by the Institutional Review Board of the New York State Psychiatric Institute.

\section{Neurological performance at age 17}

The neurological outcome measures are described elsewhere (Stokman et al. 1986). We defined the following pairs of predictor (at age seven) and outcome (at age 17) findings: astereognosis with (1) dysgraphesthesia and (2) with astereognosis; (3) dysdiadochokinesis, with difficulty in making rapid alternating movements; (4) mirror movements with mirror movements; and (5) "awkwardness', with slowness of repetitive movements. No child had had involuntary choreiform or athetotic movements at age seven; nevertheless, we looked for these movements (item 6) at age 17.

Each adolescent was seen by one of 
TABLE II

Percentages of cohort with four major neurological criteria at age seven

\begin{tabular}{|c|c|c|c|c|}
\hline \multirow{3}{*}{$\begin{array}{l}\text { Neurological } \\
\text { findings }\end{array}$} & \multirow{2}{*}{\multicolumn{2}{|c|}{$\begin{array}{c}\text { Males } \\
\text { Black White } \\
(N=136)(N=92)\end{array}$}} & \multirow{2}{*}{\multicolumn{2}{|c|}{$\begin{array}{c}\text { Females } \\
\text { Black White } \\
(N=135)(N=77)\end{array}$}} \\
\hline & & & & \\
\hline & $\%$ & $\%$ & $\%$ & $\%$ \\
\hline Mirror movements & $8 \cdot 1$ & $7 \cdot 6$ & $2 \cdot 2$ & $3 \cdot 9$ \\
\hline Dysdiadochokinesis & $23 \cdot 5$ & $18 \cdot 3$ & $8 \cdot 9$ & $11 \cdot 7$ \\
\hline 'Awkwardness' & $27 \cdot 2$ & $23 \cdot 7$ & $7 \cdot 4$ & $16 \cdot 9$ \\
\hline Astereognosis & $6 \cdot 6$ & $3 \cdot 3$ & $1 \cdot 5$ & - \\
\hline
\end{tabular}

TABLE III

Point biserial correlation coefficients for score at age 17 with predictor status at age seven ('specified predictor findings')

\begin{tabular}{lcccc}
\hline & \multicolumn{2}{c}{$\begin{array}{c}\text { Any criterion } \\
\text { Score at age 17 } \\
\text { Males }\end{array}$} & $\begin{array}{c}\text { Specified predictor } \\
\text { Females }\end{array}$ & $\begin{array}{c}\text { Males } \\
\text { Mand at age } 7\end{array}$ \\
Females \\
\hline Astereognosis & - & -0.05 & -0.05 & -0.04 \\
Dysgraphesthesia & $0.32^{* *}$ & -0.08 & $0.26^{* *}$ & 0.12 \\
Dysdiadochokinesis & $0.21^{* *}$ & -0.17 & 0.15 & -0.18 \\
Mirror movements & $0.16^{*}$ & - & $0.19^{*}$ & -0.01 \\
Invol. movements & 0.03 & -0.23 & - & - \\
Motor slowness & $0.32^{* *}$ & $0.40^{* *}$ & $0.30^{* *}$ & $0.51^{* *}$ \\
\hline
\end{tabular}

${ }^{*} \mathrm{p}<0.05 ;{ }^{* *} \mathrm{p}<0.01$.

three examiners, who were blind to neurological status at age seven. The structured protocol covered most aspects of the traditional neurological examination, but emphasized tasks similar to those which had defined 'positive' status at age seven. Each of the six neurological scores had a range of 0 (best or tied for best in the gender-specific sample) to 1 (farthest or tied for farthest from optimal). Fair to good reliability (between raters and within-subjects) was demonstrated for four of the six scores. Astereognosis and the 'choreiform twitch' proved unreliable for us.

We also set cut-off points to define present $v s$. absent classification based on these scores. Derived from small numbers, the points so set (Stokman et al. 1986) had wide confidence limits. We needed to see whether lower (more sensitive) or higher (more specific) cut-off points would change the degree of consistency observed between age seven and age 17. New cut-off points were redrawn at the farthest-from-optimal 25 scores (more sensitive) or the farthestfrom-optimal 10 scores (more specific). The results of these modifications are discussed below.

\section{Statistics}

We calculated correlation coefficients using SPSS (Nie et al, 1975). Where a $\chi^{2}$ test was used, Yates' correction was employed. One-way analysis of variance with test for linear trend was produced by SPSS subroutine 'Breakdown' and oneway analysis of variance with specified contrasts by subroutine 'Oneway' (Nie et al. 1975).

\section{Results}

Continuity from ages seven to 17 was 


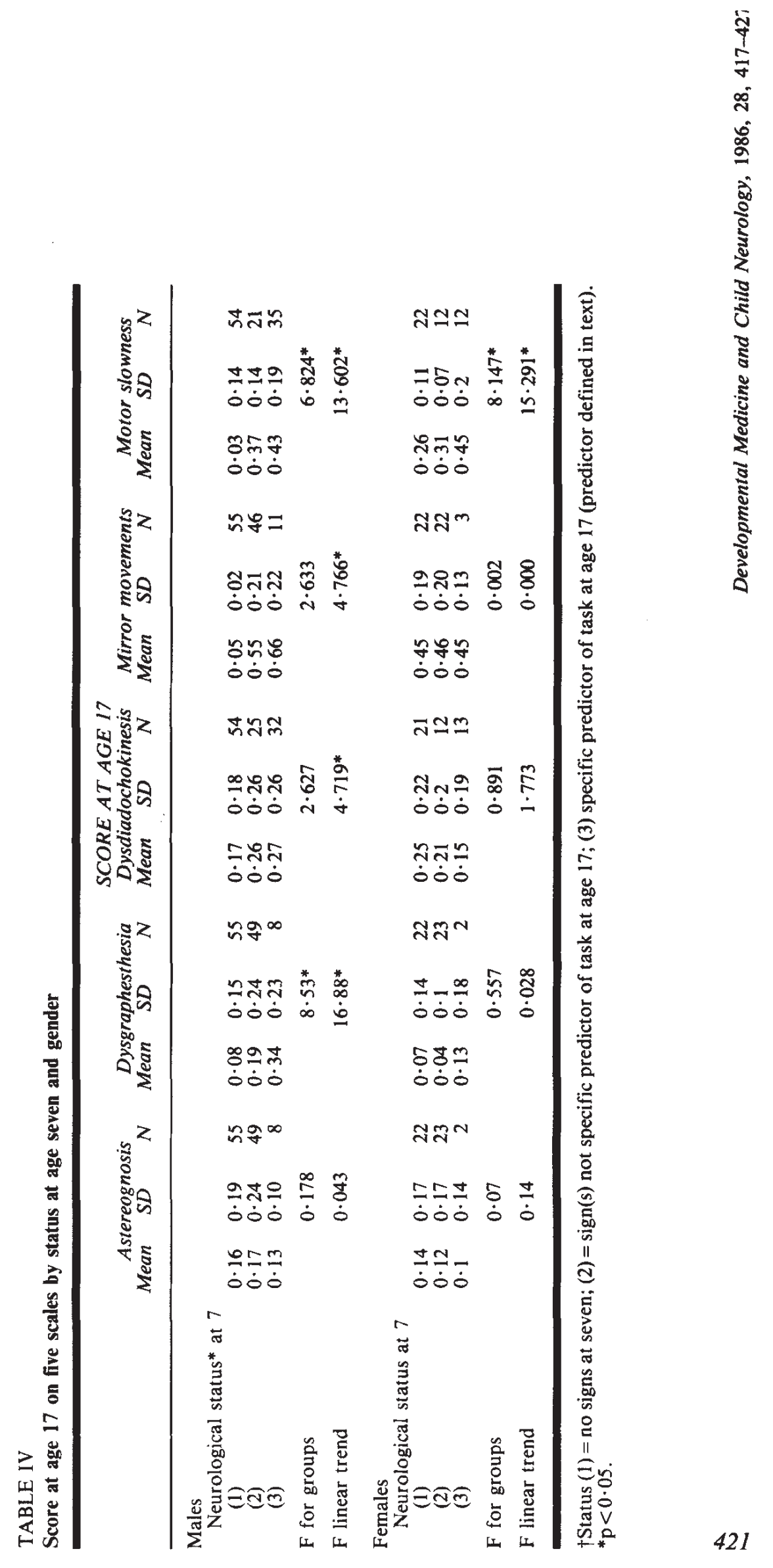


TABLE V

Proportion with finding(s) at age 17 by age seven status (any criterion finding $v s$. none) and gender

\begin{tabular}{|c|c|c|c|c|c|c|c|c|c|c|}
\hline \multirow{2}{*}{$\begin{array}{l}\text { Findings at } \\
\text { age } 7\end{array}$} & \multicolumn{2}{|c|}{ Dysgraphesthesia } & \multicolumn{2}{|c|}{ Dysdiadochokinesis } & \multicolumn{2}{|c|}{$\%$ positive at age 17} & \multicolumn{2}{|c|}{ Motor slowness } & \multicolumn{2}{|c|}{ Any of 4} \\
\hline & $M$ & $F$ & $M$ & $F$ & $M$ & $F$ & $M$ & $F$ & $M$ & $F$ \\
\hline Any & $15 \cdot 8$ & - & $22 \cdot 8$ & $12 \cdot 0$ & $21 \cdot 1$ & $12 \cdot 0$ & $21 \cdot 4$ & $20 \cdot 8$ & $61 \cdot 4$ & $32 \cdot 0$ \\
\hline None & $5 \cdot 5$ & $4 \cdot 5$ & $9 \cdot 3$ & $18 \cdot 2$ & $11 \cdot 0$ & $4 \cdot 5$ & $7 \cdot 4$ & $4 \cdot 5$ & $29 \cdot 1$ & $27 \cdot 2$ \\
\hline $\mathrm{PR} \dagger$ & $2 \cdot 9$ & - & $2 \cdot 5$ & 0.66 & 1.9 & $2 \cdot 6$ & $2 \cdot 9$ & $4 \cdot 6$ & $2 \cdot 1^{*}$ & $1 \cdot 2$ \\
\hline
\end{tabular}

$\dagger$ Prevalence ratio (see text).

*p $<0.05$.

much greater among males. On five of six comparisons the index group scored farther from optimum than the comparison group. On four measures (dysgraphesthesia, dysdiadochokinesis, mirror movements and motor slowness) the differences were significant; further, there was an ordering by status at age seven. The lowest (most normative) scores at 17 emerged from the group who had been sign-free at seven; the highest score (farthest from optimum) emerged in the group sign-positive at age seven. Intermediate values were obtained for youngsters who at seven had had a soft sign other than the predictor which corresponded to that finding at age 17 . Tables III and IV show this continuity. Females in the index group differed significantly from the comparison females on only one of the six scores, that for motor slowness (see Tables III and IV).

The relationship of status at age seven to the categorical (present vs. absent) ratings of performance at 17 is shown in Table V. The table includes only the four outcome variables with a significant relationship to status at age seven according to the tests in Table III. The measure of association, the prevalence ratio (PR), is an estimator of the relative risk for having a finding at 17, given status at age seven.

A male in the index group is two to three times more likely than a comparison male to be rated non-normative at 17 on any one of the four more reliable measures. The prevalence ratio estimates, though of moderate size, do not reflect significant differences in proportions, except for 'any of four findings' at 17.
For females, two of the prevalence ratios are of about the same size as the corresponding ones for males; however, there is more scatter, and even a reversal of direction (better performance at 17 by index females on two measures).

The results, using cut-off points lower and higher than the original ones, were also inspected in the larger (male) group. When a lower cut-off was used to declare a male abnormal at 17 , more were so characterized and the prevalence ratios fell slightly. In contrast, with a more specific cut-off point the prevalence ratios were much higher, in the four to seven range. The a posteriori cut-off points could not be applied usefully to the smaller number of girls, among whom high (non-normative) scores were less common than among the boys.

The number of findings at age seven predicted the number of findings at 17 . Boys who had had two or more criteria at age seven were six times more likely to have two or more at 17 compared to those who had had none or one $(6 / 22 v s .4 / 80)$. The examined sample of girls contained proportionately fewer $(6 / 47)$ with two or more criteria at age seven. This handful, however, were 20 times more likely to have two or more signs at $\mathbf{1 7}$ than the girls with no or one sign at seven $(3 / 6$ vs. $1 / 41$ ).

We wished to examine not only the later correlates of neurological findings at age seven, but also the correlates of change in neurological test performance over that 10-year span. Therefore change of sign status from age seven to age 17 was examined for each sex by dividing the results into four groups. 16 boys and six 
TABLE VI

Mean IQ of males by neurological status stability, age seven to 17

\begin{tabular}{|c|c|c|c|c|c|c|c|c|}
\hline \multirow{3}{*}{$I Q$ test } & \multirow{2}{*}{\multicolumn{2}{|c|}{$\begin{array}{c}-/- \\
(N=39)\end{array}$}} & \multicolumn{4}{|c|}{ Group } & \multirow{2}{*}{\multicolumn{2}{|c|}{$\begin{array}{c}+/+ \\
(N=35)\end{array}$}} \\
\hline & & & $\stackrel{+}{N=}$ & $=22$ & $(\bar{N}=$ & $(+$ & & \\
\hline & Mean & $S D$ & Mean & $S D$ & Mean & $S D$ & Mean & $S D$ \\
\hline Full-scale & $97 \cdot 6$ & $10 \cdot 0$ & $92 \cdot 2$ & $12 \cdot 3$ & $96 \cdot 4$ & $9 \cdot 6$ & $87 \cdot 7$ & $15 \cdot 2$ \\
\hline Verbal & $96 \cdot 7$ & $11 \cdot 6$ & $91 \cdot 1$ & $12 \cdot 9$ & $91 \cdot 1$ & $10 \cdot 8$ & $84 \cdot 4$ & $14 \cdot 1$ \\
\hline Performance & $98 \cdot 8$ & $10 \cdot 3$ & $94 \cdot 8$ & $13 \cdot 9$ & $102 \cdot 7$ & $8 \cdot 6$ & $93 \cdot 8$ & $17 \cdot 5$ \\
\hline
\end{tabular}

$-/-=$ no findings at either time; $+/-=$ findings at seven only; $-/+=$ findings at 17 only; $+/+=$ findings at seven and 17 ).

\section{TABLE VII}

Analysis of variance: IQ at age seven by neurological status stability age seven to 17

\begin{tabular}{lcccc}
\multicolumn{1}{c}{ IQ test } & $\begin{array}{c}\text { Over-all } \\
F\end{array}$ & $\begin{array}{c}\text { Contrast I } \\
t\end{array}$ & $\begin{array}{c}\text { Contrast 2 } \\
t\end{array}$ & $\begin{array}{c}\text { Contrast 3 } \\
\text { (Scheffe } \ddagger)\end{array}$ \\
\hline Full-scale & $4 \cdot 33^{* * *}$ & $2 \cdot 82^{* *}$ & NS & $*$ \\
Verbal & $5 \cdot 92^{* * *}$ & $2 \cdot 43^{* *}$ & $2 \cdot 44^{* *}$ & $*$ \\
Performance & $2 \cdot 03$ & $2 \cdot 37^{* *}$ & NS & NS \\
\hline
\end{tabular}

Contrast $1(+/+)$ and $(+/-)$ vs. $(-/-)$ and $(-/+)$; contrast 2 $(+/+)$ and $(-/+)$ vs. $(-/ /)$ and $(+/-)$; contrast $3(-/-)$ vs. other three groups.

${ }^{*} \mathrm{p}<0.05,{ }^{* *} \mathrm{p}<0.02,{ }^{* *} \mathrm{p}<0.01 ;$ ¥Scheffe test of SPSS (Nie et al. p. 248).

TABLE VIII

Psychiatric diagnosis of boys at age 17 by neurological status stability age seven to 17

\begin{tabular}{|c|c|c|c|c|}
\hline \multirow[b]{2}{*}{ Disorder } & \multicolumn{4}{|c|}{ Group } \\
\hline & $\begin{array}{c}-1- \\
(N=39) \dagger \\
\%\end{array}$ & $\begin{array}{c}+1- \\
(N=22) \\
\%\end{array}$ & $\begin{array}{c}-1+ \\
(N=16) \\
\%\end{array}$ & $\begin{array}{c}+/+ \\
(N=35) \\
\%\end{array}$ \\
\hline None & 62 & 46 & 69 & 49 \\
\hline Anxiety & 5 & 23 & 6 & 20 \\
\hline Affective & 18 & 27 & - & 17 \\
\hline Antisocial & 23 & 23 & 25 & 34 \\
\hline
\end{tabular}

†N with diagnosis; i.e. some boys appear more than once. 
girls who were sign-negative at age seven were judged sign-positive at 17 on one or more of the four most reliably measured tasks. This subgroup is shown as $(-/+)$ in Tables VI and VII. 22 boys and 17 girls who were sign-positive at seven were judged sign-negative at 17 . This group is shown as $(+/-)$ in Tables VI and VII. To test whether certain characteristics might distinguish the 'unstable' groups from the two other groups - signnegative at both ages (39 boys, 16 girls) or sign-positive at both ages ( 35 boys, nine girls)-we used a one-way analysis of variance. Analyses of some behaviours and some neurological findings are given only for boys; the smaller number of girls again precluded a useful four-group breakdown.

The relationship of IQ scores at age seven to change of sign status was analyzed for both sexes separately. The boys who were positive at age seven had significantly lower IQ scores than those who were negative at seven. Boys with normative neurological test performances at both seven and 17 had significantly higher full-scale and verbal IQ scores than the other three groups. There was no difference at all at age 17 in IQ scores (verbal, performance and full-scale) across the four categories of girls.

At 17 the boys showed no significant difference among the four subgroups in the presence of affective disorder, anxiety disorder or antisocial behaviors (Table VIII). Curiously, among the $22(+/-)$ boys, both affective and anxiety disorders were slightly more common than among the $35(+/ t)$ boys. The $16(-/+)$ boys were actually less likely than the 39 $(-/-)$ ones to have an affective disorder at age 17 , but this difference was not significant. A strong association emerged between soft signs at age seven and measures of affective or anxiety disorder at age 17; however the latter two disorders bore no relationship to neurological status at 17. The association is discussed at length by Shaffer et al. (1984).

We examined other factors which might account for the late appearance of soft signs, or for their disappearance. Among boys there was no significant difference across the four groups with regard to frequency of non-prescription drug use, smoking or alcohol use.

We also questioned whether a particular finding accounted for the acquisition of soft signs. None of the four major neurological tasks at 17 accounted for a disproportionate share of developing new non-normative neurological findings ( $-/+$ group). Likewise, no one of the four major criteria at age seven was over-represented in the $(+/-)$ subgroup.

\section{Discussion}

Neurological test performance in this sample is weakly but definitely consistent for boys from the ages of seven to 17 . The proportion of variation $\left(\mathrm{r}^{2}\right)$ in performance at 17 that can be described in terms of status at age seven ranges from 0.4 (dysdiadochokinesis) to 0.10 (dysgraphesthesia). The persistence of neurological test performance contradicts the idea, at least in boys, that soft signs are only maturational lag, destined to fade with age. The stability of findings depends on definition. The worse the 'positive' score at age 17, the stronger the relationship with status at age seven.

A methodological note: analysis of absent/present categories would have shown almost no statistically significant relationship in the seven- to 17 -year data (see Table V). If neurological test performance is intrinsically a continuous function, categorical analysis (used in most earlier studies) is likely to underestimate the true strength of relationships.

Two of the six hypothesized relationships did not stand up. Astereognosis at 17 was not at all related to astereognosis at age seven, perhaps because the harder astereognosis test at 17 drew too many random errors. We also found no difference at 17 between the group with any sign at seven and the group with no signs at seven with respect to the prevalence of involuntary movements (standing stock-still with feet together, eyes closed and arms outstretched).

We must now consider potential methodological problems which could exaggerate the observed 10-year consistency of soft signs. 
Random measurement error alone at either age would be expected to lower, not raise, the degree of observed consistency. However, a halo effect could simulate consistency if a behavior (e.g. restlessness, inattention) was persistent over time, and examiners are led by this obvious problem to assign a worse score than they would for the same neurological test performance by a subdued, attentive subject.

We think this is not a major problem in our study. At age 17 behavior was quite uniform and there was almost no lack of co-operation or marked inattention. The testing routine specifically omitted smalltalk so it was common to reach the inventory of medical contacts at the end of the exam without the subject's saying more than the occasional monosyllable. Three or four adolescents did clown or wander. It was impossible for the examiner to overlook these happenings, but they were unusual.

Ascertainment of cases or of controls, a source of uncertainty in earlier studies, could not have produced a spurious association. Serious selection bias due to loss to follow-up between seven and 17 is unlikely, given the high proportions followed-up. Sign-positive children in our study included all such from a group under systematic surveillance, with a comparison group drawn from the remainder of those eligible.

It is possible that soft signs persist because of a fixed but unrecognized focal or global brain-injury. It would not be notable, for example, if right-sided dysdiadochokinesis associated with a right hemiparesis, evident at ages one and seven, persisted to age 17 and heavily affected the bilateral score, or if poor performance of rapid alternating movements was lifelong in someone with a static encephalopathy. Persistence found in a sample which included such people therefore might be lost in a reference population free of such disorders. Accordingly, all analyses were repeated after removing the 10 marginal males described earlier. Changes in measures of association were trivial, and most increased the differences between groups. No previously significant association disappeared. We believe, on this basis, that suboptimal performance persists to a significant extent, even in a group carefully purged of persons who are suspected of being brain-injured.

We considered, too, that soft signs might be merely a surrogate for IQ. At age seven IQ was moderately related in boys to sign status. Correlation coefficients were -0.29 for verbal IQ -0.21 for performance and -0.30 for full-scale. However, IQ at age seven, though related to IQ at 17 , had almost no relationship to neurological status at 17 .

Further, we looked for interaction between IQ at seven and continuity of signs between seven and 17. Strong continuity confined to the lowest IQ subgroup might give an appearance of over-all continuity to the whole sample which did not obtain for those with higher IQ. For this analysis, performance IQ at seven was stratified as $<90,90$ to 109 or $>110$. The correlations between having one or more signs at age seven and score at age 17 on all four major scales were lower in the middle (largest) stratum of IQ than in the lowest and highest strata. The relationship was not confined to the lowest IQ stratum.

Finally, consistency of social behaviors could make performance on neurological examination stable over time because such performance by individuals without focal deficits depends, at least in part, on attention and willingness to co-operate. The question is whether such performance taps a neurological or a psychological construct. This question cannot be answered directly, since removing from consideration all persons known or suspected to be neurologically injured makes it impossible to validate soft signs by cross-tabulating them with other evidence of neurological damage. The question can only be approached indirectly by seeing to what extent such findings are related to established measures of affect, thought and behavior.

We did not find correlates for change of sign status between the ages of seven and 17. Perhaps the wrong exposures were examined, or the failure is methodological. With the loss of statistical power due to analyzing subgroups and with errors in selfreporting (e.g. of drug use), detection of 
moderate-sized effects becomes improbable. Therefore this study cannot answer two of the three developmental questions posed in the introduction. However, it does give sound evidence that among male children free of focal or global neurological deficits, neurological test performance is consistent over a 10-year span. Non-normative performance by boys is not merely maturational lag; that by girls is.

Accepted for publication 22nd October 1985.

\section{Acknowledgements}

We thank the adolescents and their families for their participation. We are also grateful to Dr. Marguerite Gates, the Project Director of the Columbia cohort of the NCPP. Among many colleagues essential in arranging the follow-up, we thank especially Dee Matthews and Suzanne Hess. Tony Pikus assisted with data processing. Nora Giurici and Maryjo D'Elia typed the manuscripts. This work was made possible in part by NIMH Center Grants $\mathrm{MH}$
30906-01A and MH 30906-03, NIMH Education Grant \#2T01 MH 07715-17 and by the Research Associate Program created by the New York State Legislature, Office of Mental Hygiene, Division of Research. Computer Facilities were supported by NIMH Clinical Research Grant MH 30906-05.

\section{Author's Appointments}

*Stephen Q. Shafer, M.D., M.P.H. Assistant Clinical Professor of Public Health and Neurology, G.H. Sergievsky Center, Columbia University.

Cornelis J. Stokman, Ph.D., Director of Research, Mid-Hudson Psychiatric Center.

David Shaffer, M.B., M.R.C.P., F.R.C. Psych., D.P.M. Director, Division of Child Psychiatry, Columbia University.

Stephen K-C. Ng, M.B., B.Ch., M.P.H., Research Associate, G.H. Sergievsky Center.

Patricia A. O'Connor, Ph.D., Associate Professor of Psychology, Russell Sage College, Troy, New York.

Irvin S. Schonfeld, Ph.D., Research Associate, Division of Child Psychiatry, Columbia University.

*Correspondence to first author at G.H. Sergievsky Center, 630 W. 168th Street, New York City, N.Y. 10032.

\section{SUMMARY}

To assess 'soft-sign' persistence and its correlates outside a referred sample, 159 members of a local birth cohort of the United States National Collaborative Perinatal Project were traced and their performance on six neurological test scales was measured at age 17 by examiners blind to their status at age seven. A comparison group was also formed, who had been 'sign'-free at age seven. On four of the six tests (dysdiadochokinesis, mirror movements, dysgraphesthesia and motor slowness) index boys did significantly worse than the comparison boys; by contrast, index girls scored significantly worse than comparisons only on motor slowness.

\section{RÉSUMÉ}

Permanence sur dix ans des tests de performance neurologique chez des enfants sans signes neurologiques en foyer

Pour apprécier la permanence des 'signes frustes' et sa corrélation avec un échantillon de référence, 159 membres d'un groupe local faisant partie de l'United States National Collaborative Perinatal Project ont été suivis et leurs performances à six échelles de tests neurologiques ont été mesurées à l'âge de 17 ans par des juges ignorants de leur état à l'âge de sept ans. Un groupe de comparaison a été constitué, sans aucun signe aberrant á l'âge de sept ans. Pour quatre des six tests (dysdiadococinésie, mouvements en miroir, dysgraphesthésie et lenteur motrice) les garçons du groupe expérimental eurent des résultats significativement moins bons que ceux du groupe de comparaison; en revanche, les performances du groupe expérimental des filles étaient inférieures au groupe de comparaison uniquement pour la lenteur motrice.

\section{ZUSAMMENFASSUNG}

Gleichbleibende neurologische Testergebnisse bei Kindern ohne fokale neurologische Ausfälle

Um die Persistenz neurologischer Minimalsymptome in einer willkürlich gebildeten Gruppe zu untersuchen, wurden 159 Patienten eines lokalen Geburtenkollektivs des United States National Collaborative Perinatal Project herausgezogen und im Alter von 17 Jahren auf ihre Leistungen bei sechs neurologischen Tests von Untersuchern bewertet, die ihren Leistungsstand im Alter von sieben Jahren nicht kannten. Außerdem wurde eine Vergleichsgruppe aus Kindern gebildet, die mit sieben Jahren unauffällig waren. Bei vier der sechs Tests (Diadochokinese, Spiegelbewegungen, Schreibschwäche und motorische Verlangsamung) waren die Jungen der Index-Gruppe signifikant schlechter als die Jungen der Vergleichsgruppe; die Mädchen der Index-Gruppe dagegen waren nur bei der motorischen Verlangsamung signifikant schlechter als die Kontrollen.

\section{RESUMEN}

Constancia de diez años en la realización de tests neurológicos en niños sin ningún déficit neurológico focal Para valorar la persistencia de 'signos blandos' y su correlación fuera de una muestra de referencia, 159 miembros de un grupo local de nacimientos del Proyecto Nacional Colaborativo Perinatal de los Estados Unidos fueron seguidos y su realización en seis escalas de tests neurológicos fueron medidas a la edad de 17 affos, por examinadores ignorantes de su situación a los siete años de edad. Se formó también un grupo comparativo, que no habia presentado ningún signo a los siete años de edad. En cuatro de los seis tests (disdiadococinesia, movimientos en espejo, disgrafestesia y lentidud motora) los muchachos problema lo 
hicieron significativamente peor que los del grupo control. Por contraste las chicas tuvieron un puntaje

significativamente peor que las control sólo en el movimiento lento.

References

Adams, R. M., Kocsis, J, J., Estes, R. E. (1974)

'Soft neurological signs in learning-disabled children and controls.' American Journal of Diseases of Children, 128, 614-618.

Hertzig, M. E. (1982) 'Stability and change in nonfocal neurological signs.' Journal of the American Academy of Child Psychiatry, 21, 231-236.

Nichols, P., Chen, T.-C. (1981) Minimal Brain Dysfunction: a Prospective Study. Hillsdale, N.J.: Lawrence Erlbaum.

Nie, N. H., Hull, C. H., Jenkins, J. G., Steinbrenner, K., Bent, D. H. (1975) Statistical Packages for the Social Sciences, 2nd Ed. New York: McGraw-Hill.

O'Connor, P., Shaffer, D., Stokman, C., Shafer, S. (1986). 'A neuropsychiatric follow-up of children in the Collaborative Perinatal Project: a longitudinal study of neurological signs in childhood.' In Mednick, S., Harway, M. (Eds.) Longitudinal Research in the United States. New York: Praeger Scientific Publications (in press).

Quitkin, F., Rifkin, A., Klein, D. F. (1976) 'Neurologic soft signs in schizophrenia and character disorder.' Archives of General
Psychiatry, 33, 845-853.

Shafer, S. Q., Shaffer, D., O'Connor, P. A., Stokman, C. J. (1984) 'Hard thoughts on soft signs.' In Rutter, M. (Ed.) Developmental Neuropsychiatry. Edinburgh: Churchill Livingstone; New York: Guilford Press. pp. 133-143.

Shaffer, D. (1978) "'Soft" neurological signs and later psychiatric disorder-a review.' Journal of Child Psychology and Psychiatry, 19, 63-65.

- O'Connor, P. A., Shafer, S. Q., Prupis, S. (1984) 'Neurological soft signs: their significance for behavior and their origins.' In Rutter, $\mathbf{M}$. (Ed.) Developmental Neuropsychiatry. Edinburgh: Churchill Livingstone; New York: Guilford Press. pp. 144-163.

Shapiro, T., Burkes, L., Petti, T. A., Ranz, J. (1978) "Consistency of "nonfocal" neurological signs.' Journal of the American Academy of Child Psychiatry, 17, 70-79.

Stokman, C. J., Shafer, S. Q., Shaffer, D., Ng, S. K-C. O'Connor, P. A., Wolff, R. W. (1986) 'Assessment of neurological soft signs in adolescents: reliability studies.' Developmental Medicine and Child Neurology, 28, 428-439. 